\section{Efecto de la masticación de la hoja de coca sobre las estructuras de la cavidad oral}

\section{Effect of chewing coca leaf on oral cavity structures}

\section{Resumen}

La masticación de hoja de coca es un hábito arraigado en varias localidades de Latinoamérica, sobre todo en las zonas andinas. Dicho hábito se ha relacionado con posibles alteraciones en diversos componentes de la cavidad oral. El propósito de esta revisión es describir los cambios que sufren las estructuras de la cavidad bucal por la masticación de hojas de coca. Se expondrán diversos estudios donde se encuentra que la frecuencia del consumo de la hoja, además de la sustancia alcalina que se emplea en la masticación, afecta a los tejidos duros y blandos de la cavidad oral. Se concluye en la revisión que la masticación de la hoja de coca conlleva a la aparición de pigmentaciones de la mucosa oral, desgaste dental y a enfermedades periodontales.

Palabras clave: Patología bucal; Coca; Masticación (fuente: DeCS BIREME).

\begin{abstract}
Chewing coca leaves is a rooted habit in several localities in Latin America, especially in the Andean areas. This habit has been related to possible alterations in various components of the oral cavity. The purpose of this review is to describe the changes that oral cavity structures undergo by chewing coca leaves. Several studies will be presented where it is found that the frequency in addition to the alkaline substance used in chewing coca leaf affects the hard and soft tissues of the oral cavity. It is concluded in the review that chewing coca leaf leads to pigmentation of oral mucosa, dental wear and periodontal diseases.
\end{abstract}

Keywords: Oral pathology; Coca; Chewing (source: MeSH NLM).

\section{Artículo de Revisión}

Linda Patricia Lucas Espeza ${ }^{1, a}$, Nelly Lam Figueroa ${ }^{1, b}$ Elías Ernesto Aguirre Siancas ${ }^{1, c}$

${ }^{1}$ Universidad Nacional Mayor de San Marcos. Lima, Perú.

a Cirujano Dentista.

b Doctora en Medicina.

c Doctor en Neurociencias.

\section{Correspondencia:}

Linda Patricia Lucas Espeza

Correo electrónico: linda.lucas@unmsm.edu.pe Urb. Villa Vitarte Mz B lote 21 - Ate, Lima, Perú.

\section{Coautores:}

Nelly Lam Figueroa

nlamf@unmsm.edu.pe

Elías Ernesto Aguirre Siancas

eaguirres@unmsm.edu.pe

\section{Editora:}

María Antonieta Pérez Flores

Universidad de Concepción, Chile.

Conflicto de intereses: no existe conflicto de intereses

Fuente de financiamiento: recursos propios del autor

Recibido: $15 / 07 / 19$

Aceptado: 22/10/19

Publicado: $27 / 11 / 19$ 


\section{Introducción}

Erythroxylum coca o coca es una planta ancestral con diversas propiedades siendo oriunda de América del Sur sobretodo de Perú y Bolivia y está compuesta por 14 alcaloides ${ }^{1}$. Dentro de las propiedades que se le atribuye destacan la de producir analgesia, el estimular el sistema nervioso, su capacidad terapéutica en problemas digestivos y del mal de altura y su capacidad mitigadora del apetito, la sed y el cansancio ${ }^{2}$. Además, en este aspecto sedestaca su alto contenido proteico ${ }^{3}$.

Perú es el segundo país con mayores superficies de plantaciones de coca ${ }^{4}$. Además, según reportes estadísticos, casi tres millones de personas mastican hoja de coca al año, considerándose masticadores habituales aquellos que lo practican de 3 a 7 veces por semana, destacando en dicho grupo la presencia de agricultores y ganaderos de las zonas de los andes peruanos y bolivianos ${ }^{5}$.

El masticador habitual de la hoja coca forma el bolo de coca y lo mantiene entre las mejillas y la mandíbula durante horas. Dicho hábito, con el tiempo, desencadena alteraciones periodontales y dentarias ${ }^{6}$. En muchas ocasiones durante la masticación de la hoja de coca suele añadirse la tocra, sustancia alcalina, que causa variación del $\mathrm{pH}$ salival, siendo un factor desencadenante de enfermedades bucales ${ }^{6}$. Las enfermedades bucales son un problema de salud pública, encontrando dentro de las patologías orales más frecuentes a la caries y a la enfermedad periodontal, siendo esta última uno de los factores predisponentes de las enfermedades sistémicas ${ }^{7,8}$.

La masticación habitual de la hoja de coca se relaciona con un incremento en el desgaste dentario y en la enfermedad periodontal. Se entiende que dichas alteraciones son causadas tanto por efectos físicos, como la fricción continua de las piezas dentarias entre sí, así como efectos químicos, debido al contacto entre las sustancias usadas y las estructuras orales, las cuales poco a poco se van deteriorando ${ }^{9}$. Sin embargo, dicha relación aún no tiene una amplia evidencia y es debido a ello que el presente artículo revisará dicha temática.

\section{Revisión de la literatura}

La coca fue domesticada aproximadamente hace unos 4000 años. La extensión de su cultivo abarcó desde la actual Nicaragua hasta Chile pasando por la Cordillera de los Andes. Etimológicamente proviene del vocablo aymara "Kkoka", que significa arbusto y sus hojas contienen diversos alcaloides con efecto psicoactivo estimulante ${ }^{10,11}$.

Actualmente el uso tradicional de la hoja de coca es en forma de chacchado (masticación de la hoja de coca) o acullico por sus efectos antifatigantes y reductores del apetito, y en menor proporción es utilizada en forma de infusión (mate de coca) ${ }^{12}$. En el Perú, durante el año 2013 se registró que 3464681 personas compraron hoja de coca al menos una vez y sus edades fluctuaron entre 12 y 65 ańos, siendo la mayor cantidad de consumidores los residentes de la sierra $(68,5 \%)$ seguida de Lima Metropolitana y Callao (15\%) ${ }^{13,14}$.

\section{Uso}

El hábito de la masticación de la hoja de coca es una actividad social, inicialmente se retira las hojas consideradas sucias o mal trechas ${ }^{15}$. Las hojas escogidas son colocadas a un lado de la boca, con una pequeńa cantidad de Ilipta o tocra (sustancia alcalina) impregnándolas de saliva y moldeándolas con la lengua hasta formar un bolo. Luego el bolo se mantiene sin mascarlo y se absorbe el jugo hasta que dicho bolo pierda sabor, finalmente se expulsa y se empieza nuevamente a escoger las hojas que reiniciarán el proceso ${ }^{11}$.

\section{Efectos}

Dicho hábito tiene efectos tanto a nivel sistémico como a nivel oral; así, a nivel sistémico sus alcaloides bloquean el hambre, el cansancio y favorece el funcionamiento intestinal, debido a ello muchos de sus consumidores lo hacen en su jornada laboral ${ }^{16}$. Aproximadamente se extrae un promedio de $86 \%$ de los alcaloides y de ellos el $80 \%$ es cocaína. Entre los chacchadores también se han encontrado manifestaciones sistémicas agudas como taquicardia, ligero aumento de presión arterial y de la temperatura corporal así como también alteraciones respiratorias. Dentro de las manifestaciones de carácter crónico se puede nombrar: malnutrición, hepatomegalia, linfadenopatias y deficiencias visuales ${ }^{17,18}$. A nivel oral el chaccheo puede producir alteraciones en la mucosa bucal donde se ha encontrado relacionado con quemaduras y con el desarrollo de insensibilización orgánica al combinar la hoja de coca con la cal. El masticador de la hoja de coca crónico mantiene chacchando el bolo de coca durante un tiempo promedio de 6 horas diarias, lo cual provoca alteraciones en la mucosa oral y debido a la acción mecánica continua, puede desencadenar paraqueratosis, acantosis, hiperqueratosis, leucoedema, leucoplasia y zonas blanquecinas, rugosas y agrietadas 19 , dichas características se limitan principalmente a la zona de la lengua o encía vestibular en relación a la zona del hábito de masticación de la hoja de coca ${ }^{20}$. También a consecuencia del chaccheo prolongado la cavidad oral presenta pigmentaciones de color violáceo - verdoso en tejido blando y duro ${ }^{15}$.

En el distrito de Laraos - Provincia de Yauyos - Lima se evaluó a 60 habitantes, de los cuales 30 eran masticadores de hoja de coca y 30 no masticadores, entre las edades de 40 a 61 años; resultó que la irritación mecánica química y crónica producida por el hábito de la masticación de coca generó acantosis e hiperparaqueratosis en la mucosa de la encía entre los chacchadores ${ }^{20}$. Asimismo Bartens ${ }^{9}$ observó en 29 biopsias (96,67\% de toda la muestra) una reacción inflamatoria en la mucosa gingival, lo cual concuerda con el estudio de Ayón 20 , quien encontró similar resultado $(96,67 \%)$ en una muestra también de 30 biopsias. El chaccheo también puede producir alteraciones en dientes y periodonto, así en diversos estudios realizados consideran que el desgaste dentario y la enfermedad periodontal tienden a incrementarse con el hábito del chacchado, la primera de ellas es causada tanto por efectos físicos (abrasión) 
como químicos (erosión) y la segunda por el contacto de las sustancias usadas en el chacchado con las estructuras de soporte dentario, las cuales son debilitadas ${ }^{19,21}$. En los quechuas la permanente masticación de hojas de coca genera lesiones en boca como: ulceración, necrosis, recesión de los tejidos gingivales y una severa erosión del esmalte y la dentina ${ }^{22}$, además la continua masticación de hojas de coca produce un desgaste de los dientes de forma anormal observadas en las superficies oclusales, así lo demuestra en su investigación Trujillo y Calderón ${ }^{23}$. Así, la masticación continua de la hoja de coca se asocia a un remodelado en la forma de las arcadas y el plano de oclusión ${ }^{24}$.

En otro estudio desarrollado en el centro poblado de San Juan de la Libertad del distrito de Huasahuasi, Provincia Tarma - Junín se examinó a 100 pobladores, 50 masticadores de la hoja de coca y 50 no masticadores, entre las edades de 20 - 80 años. Dentro del grupo de chacchadores se encontró que siete empezaron el hábito hacía menos de 5 años, 13 desde hacía 5 a 10 años, y 30 desde hacía más de 10 años. El 86\% de los chacchadores lo hacía de forma diaria y el $74 \%$ usaba más de dos bolos; entre los hallazgos se tuvo que los masticadores que empezaron el hábito hacía menos de 5 años tuvieron menos CPOS $(\mathrm{p}<0,05)$ que los masticadores que empezaron hacía más de diez años ${ }^{25}$. También Torres y Cisneros ${ }^{26}$ evaluaron, en Cajamarca, a 365 chacchadores de coca entre los 20 y 60 años de edad de ambos sexos, encontrando que el índice CPOD fue más alto $(10,22)$ entre los de 50-60 años, y más bajo $(5,62)$ entre los de 20-29 años. El índice CPOD total correspondió a 7,56 por consiguiente respecto a criterios epidemiológicos el nivel de severidad del índice CPOD en chacchadores de coca es más alto a medida que pasa el tiempo. En otros estudios realizados por Ramos ${ }^{25}$ y Paye ${ }^{27}$ el índice correspondió a 11,58 y 18,1 indicando niveles de severidad muy altos similar a la investigación de Torres y Cisneros ${ }^{26}$. Por tanto, el tiempo de antigüedad en el hábito es un factor directamente relacionado con el incremento del índice CPOD en la población de chacchadores de hoja de coca. Investigaciones realizadas en el departamento de Huánuco determinaron que existe correlación directa entre enfermedad periodontal y la masticación habitual de la hoja de coca y con predominio del sexo femenino ${ }^{28,29}$. Alor ${ }^{30}$ en el distrito de Huallanca, Región Ancash evaluó 169 pobladores con el hábito de masticar hoja de coca, mayores de 18 años y de ambos sexos resultando que la frecuencia de consumo de hoja de coca se relacionó con la caries dental.

Adicionalmente, el efecto de la masticación de la hoja de coca con la tocra genera mayor alteración de las estructuras blandas y duras de la cavidad oral, como así lo demuestran diversas investigaciones ${ }^{19,20,22,23}$.

\section{Conclusiones}

Se concluye que el hábito de la masticación de la hoja de coca conjuntamente con la tocra o llipta (sustancia alcalina) es practicado mayoritariamente en la población andina, dicho hábito origina la aparición de alteraciones en el tejido blando y duro de la cavidad oral, además el factor tiempo es perjudicial para el inicio de dichas alteraciones, de esta manera se pone en riesgo la salud de la persona.

Finalmente, se observan muy pocos estudios sobre este tema debido a que es una temática costumbrista y autóctona que comprende exclusivamente a países productores como Perú y Bolivia.

\section{Referencias bibliográficas}

1. Novak M, Salemink CA, Khan I. Biological activity of the alkaloids of Erythroxylum coca and Erythroxylum novogranatense. J Ethnopharmacol. 1984;10(3):261-274.

2. Minaya P. Determinación de la actividad antibacteriana "in vitro" del extracto etanólico de la hoja de Erythroxylum novogranatense var truxillense (coca) frente a bacterias orales cariogénicas [Tesis de Bachiller]. [Lima]: Facultad de Odontología, Universidad Nacional Mayor de San Marcos; 2008. 58p.

3. Ramos R. Fraccionamiento químico de la hoja de coca y obtención de un producto rico en proteínas. Rev Soc Quím Perú. 2005;71(1):3-10.

4. Holge K, Vallejos L, Herrera T, Lumbre P, Galvez G, Gutarra A, et al. Perú Monitoreo de cultivos de coca. 16a ed. Lima: UNODC; 2018.

5. Rospigliosi F, Blondet C, Llorens J. El consume tradicional de la hoja de coca en el Perú. la ed. Lima: Instituto de Estudios Peruanos; 2004.

6. Coronel A. Estudio comparativo de la prevalencia de caries, enfermedad periodontal y abrasión entre un grupo de sujetos con el hábito de masticación de hojas de coca y un grupo control en la comunidad de Apaycanchilla, provincial de Tarma [Tesis de Bachiller]. [Lima]: Facultad de Estomatología, Universidad Peruana Cayetano Heredia; 1988.50 p.

7. Webb D, Barrientos S, Méndez C, Rodríguez A. Frecuencia y características de hallazgos endodónticos en radiografías panorámicas digitales. Odontoestomatologia. 2017;19(29):76-84.

8. Peña M, Calzado M, Gonzáles M, Cordero S, Azahares H. Patógenos periodontales y sus relaciones con enfermedades sistémicas. Medisan. 2012;16(7):1137-1148.

9. Bartens GF. Cambios histológicos en el epitelio de la mucosa del carrillo, en sujetos masticadores de hojas de coca, pertenecientes a la comunidad de Quircan, distrito de San Francisco, provincia de Ambo, departamento de Huánuco [Tesis de Bachiller]. [Lima]: Facultad de Estomatología, Universidad Peruana Cayetano Heredia; $1988.50 \mathrm{p}$.

10. Tellez J, Cote M. Efectos toxicológicos y neurosiquiátricos producidos por consumo de cocaína. Rev Fac Med Univ Nac Colomb. 2005;53(1):11-26.

11. Villena M, Sauvain M. Usos de las hojas de coca y salud pública. 1a ed. La Paz: Instituto Boliviano de Biología de Altura; 1997.

12. Martínez-Vargas A, Salas M, Rojas M. La aplicación de la convención única de las naciones unidas de 1961 y los usos medicinales de derivados de opio, hoja de coca y marihuana. 1a ed. Lima: Cedro; 2016. 
13. Instituto Nacional de Estadística e Informática, Comisión Nacional para el desarrollo y vida sin drogas. Análisis de los resultados de la encuesta de hogares sobre demanda de la hoja de coca 2013. 2da Ed. Lima: INEI; 2015.

14. Revilla-Zuñiga J, Riveras-Encinas MT, Lizardo C. Diagnóstico erróneo de psicosis inducida por cocaína en una persona con esquizofrenia y masticadoras de hojas de coca. Rev Neuropsiquiatr. 2016;79(2):120-126.

15. Esteva C. Los usos de la coca en Chinchero, Cuzco (Perú). Sociedad de Ciencias Naturales. 1971;23(4):430443.

16. Aibar-Ozejo ME. Los efectos del consumo de la hoja de coca. Rev Per Obst Enfer. 2006;2(1):77-80.

17. Rojas RA. Eficacia antibacteriana in vitro del extracto de hoja de coca en comparación con clorhexidina frente a staphylococcus y streptococcus [Tesis de Bachiller]. [Huánuco]: Facultad de Odontología, Universidad de Huánuco; 2011.81 p.

18. Domic Z. Revisión crítica bibliográfica y consideraciones generales acerca del masticado de coca. Cocaína 1985-Actas del Seminario Interamericano sobre Aspectos Médicos de la Coca y la Cocaína. Lima: Editorial F. R. Jeri; 1985.

19. Goicochea I. Estudio de la cavidad bucal en los sujetos habituados a la masticación de hojas de coca en la hacienda Collambay-Trujillo [Tesis de Bachiller]. [Lima]: Facultad de Odontología, Universidad Nacional Mayor de San Marcos; 1954.50 p.

20. Ayón E, Chu MP. Cambios histopatológicos de la mucosa gingival en masticadores de hoja de coca varones del distrito de Laraos, provincia de Yauyos. Kiru. 2005;2(1):25-26.

21. Ungaro M. Patología oral en masticadores de hojas de coca [Tesis Doctoral]. [Lima]: Facultad de Estomatología, Universidad Peruana Cayetano Heredia; 1972. 49 p.
22. Solórzano E, Dávila L, Quiñones B. Efectos clínicos e histológicos de la cocaína sobre el periodonto de protección. Rev Asoc Odontol Argent. 2003;91(3):222-225.

23. Trujillo A, Calderón A. El desgaste dental. ¿Un método fiable para la estimación de la edad?. Estrat Critic. 2011;5(1):497-498.

24. Raymond JL, Pimentel I, Vignolo R. Tratamiento ortopédico de las maloclusiones Clase III: masticación y plano oclusal. Ortodoncia Clínica. 2009; 12(4): 192-193.

25. Ramos EA. Efectividad de la masticación de la hoja de coca en la prevención de la caries dental en el Centro poblado de San Juan de la Libertad Huasahuasi-Tarma [Tesis de Bachiller]. [Lima]: Facultad de Odontología, Universidad Nacional Federico Villareal; 2008. 24 p.

26. Torres CG, Cisneros M. Prevalencia de caries dental según el índice CPOD en pacientes adultos chacchadores de hojas de coca. Revista UAP. 2016;3(2):5-16.

27. Payé EM. Prevalencia de caries dental en consumidores de erythroxylum coca con y sin llipta en la Comunidad de Ccatacha-Puno [Tesis de Bachiller] [Puno]: Facultad de Odontología, Universidad Nacional del Altiplano;2014. 76 p.

28. Torres VK. Enfermedad periodontal asociado al consumo habitual de la hoja de coca y el cal en personas de 40 a 70 años Huánuco [Tesis de Bachiller] [Huánuco]: Facultad de Odontología, Universidad de Huánuco; 2016.76 p.

29. Alminco D. Características clínicas de la mucosa oral en pobladores con hábito de coqueo del distrito de Conchamarca Huánuco [Tesis de Bachiller] [Huánuco]: Facultad de Odontología, Universidad de Huánuco; 2017. 96 p.

30. Alor VE. Hábito de masticar hoja de coca y su relación con la caries dental en los pobladores del centro poblado Llacuash del distrito de Huallanca región Ancash [Tesis de Bachiller] [Ancash]: Escuela profesional de Estomatología, Universidad Alas Peruanas; 2018. 84 p. 